\title{
UM PROJETO DE INTERVENÇÃO SOCIAL VISTO PELOS SEUS AGENTES - ESTUDO PSICOSSOCIAL DO PROGRAMA DE SAÚDE DA FAMÍLIA
}

\author{
Ana Maria Blanques
}

Resumo: O Programa de Saúde da Família (PSF) foi escolhido como objeto deste estudo por ser um projeto de intervenção social que pretende promover maior autonomia da população para resolver problemas relativos à saúde no território. $O$ material obtido em entrevistas com os profissionais foi analisado por meio de categorias agrupadas em dois blocos temáticos: concepção do trabalho - aquelas que se referem às atividades, e de sujeito em que se reúnem as ideias sobre as pessoas envolvidas. Os conteúdos revelam que o programa não atinge as mudanças previstas. O conceito de território é incipiente, a participação é precária e as doenças se mantêm em lugar privilegiado. As pessoas da população são referidas num conjunto que é caracterizado por faltas, carências, necessidades e, em muitos casos, são identificadas aos próprios entrevistados. A ajuda mobiliza as ações e é o eixo a partir do qual os atores compreendem sua própria atuação.

Palavras-chave: Programa Saúde da Família. Intervenção social. Estudo psicossocial.

\section{Introdução}

Em uma ação direta no território, a equipe de Saúde da Família tem a função de assistir de maneira integral às famílias de uma determinada área, ao mesmo 
tempo em que desenvolve atividades no sentido de possibilitar a participação comunitária na mudança das condições para produção de melhor qualidade de vida. A proposta, como uma intervenção social que implica na participação da comunidade para promover desenvolvimento social e maior autonomia da comunidade para gerenciar seus próprios problemas, foi o que estimulou a produção do presente estudo.

$\mathrm{Na}$ ação de suporte psicológico com profissionais das equipes de Saúde da Família na região Norte da cidade de São Paulo, foi possível observar que existia uma distância entre a proposta e o trabalho concretizado. Entender a relação entre o modelo proposto, com seus princípios e diretrizes, e aquele efetivamente colocado em prática a partir da expectativa e valores das pessoas implicadas no trabalho cotidiano, foi o objetivo desta pesquisa, desde que, revelar as coincidências ou diferenças entre a proposta e a prática do projeto poderia ajudar a compreender alguns fatores que interferem no desenvolvimento de um projeto de intervenção.

As ideias de participação na área de saúde, não são novas nem exclusivas do Saúde da Família, pois desde a declaração de Alma-Ata em 1978, se registra um movimento sanitário que prioriza a promoção da saúde com ênfase na participação qualificada da comunidade para o desenvolvimento de condições mais saudáveis de vida. A OMS tem se dedicado ao assunto, pois compreende saúde como, ao mesmo tempo, resultado e pré-requisito do desenvolvimento da comunidade (Kahassay \& Oakley, 1999).

"Participação emancipatória entendida como a ação de ser (fazer) parte de processos de transformação social que suponham não uma passividade dos atores" (Tassara \& Ardans, 2003, p. 17, grifos nossos), que se incluem de forma coletiva em todas as fases do processo de construção das políticas públicas, sustentados na reflexividade e superando a ação caritativa é a compreensão a partir da qual se pretende acompanhar o processo que o Programa de Saúde da Família deveria desencadear e quais seriam os aspectos que funcionariam como facilitadores ou como obstáculos para a construção de um projeto de participação emancipatória.

\section{O Programa de Saúde da Família (PSF)}

À grande virada na proposição da atenção à saúde que ocorreu com a elaboração da Constituição Brasileira de 1988 deveria corresponder outra mais árdua que significaria sua implantação, especialmente num momento de expansão do pensamento neoliberal, cuja tendência é a valorização da competitividade entre equipamentos privados, estimulada pelas regras do mercado, em detrimento dos serviços públicos. A cria- 
ção do SUS (Sistema Único de Saúde) representou a grande reforma, pois introduziu mudanças consistentes no modo de operação do sistema (Viana \& Dal Poz, 1998). Este modelo definiu alguns princípios como:

universalismo para as ações de saúde, a descentralização municipalizante e um novo formato organizativo para os serviços sob a lógica da integralidade, da regionalização e da hierarquização, com definição de porta de entrada. Além disso, as ações preventivas e curativas passaram a ser responsabilidade dos gestores públicos. (p. 13)

Esse novo modelo assistencial que inclui a criação de um sistema nacional de saúde previa ainda o envolvimento de outros atores (prestadores de serviço, trabalhadores, gestores, usuários) na gestão, pretendendo uma gestão participativa.

O Ministério da Saúde, que em 1991 já incorporara o PACS (Programa de Agentes Comunitários de Saúde), modelo utilizado por alguns estados, para áreas menos acessíveis, onde os índices de morbimortalidade materna e infantil eram considerados graves, em 1994 decide pela implantação do Programa de Saúde da Família, com a inclusão de profissionais como o médico, enfermeiro e auxiliares de enfermagem constituindo a Equipe da Saúde da Família. O PSF, então, foi concebido como estratégia de reorganização do SUS, reordenamento do modelo de atenção para reorientação e reorganização dos serviços na ampliação da cobertura a partir do território e busca de promoção da saúde (Sousa \& Hamann, 2009).

Como uma nova estratégia estruturante, devia evitar o eixo da intervenção médica e buscar a integração de fato com a comunidade (Brasil, 2003).

Esta estratégia é mais do que isto, é mais ampla, significa mudar o paradigma da assistência médica transformando o modelo assistencial.Significa levar em conta necessidades e demandas da população. $O$ foco do sistema de saúde passa de cuidados episódicos de indivíduos em hospitais para promoção de saúde na comunidade. Significa também reconhecer que o setor de saúde não tem potência para proporcionar saúde plena à população. (Faleiros, 2003, p. 62)

A reorganização dos serviços de saúde proposta pelo PSF se faz a partir de um território onde a equipe instalada deve cadastrar a população, levantando os dados necessários que permitam reconhecer e enfrentar os problemas identificados, e assim montar as estratégias de ação para organização dessas áreas. Em 2004, quando foi realizado este estudo, a equipe de Saúde da Família era composta por um médico generalista ou da família, um enfermeiro, um ou dois auxiliares de enfermagem e de 4 a 6 agentes comunitários se responsabilizavam por uma área onde vivem cerca de mil famílias e até 4500 pessoas. 
Em 2006, com a portaria no.648, do Ministério da Saúde (Brasil, 2006) determinou-se uma população de 3000 habitantes a ser atendida por cada equipe que passou a contar também com um dentista e um auxiliar ou técnico em odontologia (equipe de saúde bucal).

Os agentes comunitários de saúde, como integrantes da comunidade, ganham relevância especial uma vez que eles funcionam como elementos facilitadores da inserção da equipe na comunidade (Brasil, 2001; Veras \& Carvalho, 2000).

Como um programa que visa substituir as práticas convencionais de assistência por um novo processo de trabalho centrado na vigilância à saúde, se estrutura a partir dos seguintes eixos:

- integralidade e hierarquização: está inserida no nível local de atenção, mas pertence a uma rede integrada nos vários níveis de referência dos serviços de forma a assegurar cuidado integral;

- territorialização e adscrição da clientela: trabalha com território de abrangência e é responsável pelo cadastramento e acompanhamento da população adscrita a esta área.

- equipe multiprofissional: a equipe de Saúde da Família é composta minimamente por um médico generalista ou médico de família, um enfermeiro, um auxiliar de enfermagem e de quatro a seis agentes comunitários de saúde;

- humanização do atendimento: aqui é focalizado o fortalecimento do vínculo entre equipe de saúde e as famílias, o que é facilitado pela proximidade com que é caracterizado o trabalho;

Na cidade de São Paulo a implantação do PSF iniciou-se pontualmente na região de Itaquera em 1996 sob nome de Qualis. Em 2001, com a adesão do município ao SUS, tendo com eixos estruturantes a municipalização e distritalização (Bousquat, Cohn, \& Elias, 2006), foi ampliado para grande parte da periferia da cidade "destinando-se aos segmentos populacionais com maiores carências ou que vivenciem diferentes graus de exclusão social" (Marsiglia, Silveira, \& Carneiro Junior, 2005). Em geral, o programa destina-se às famílias com dificuldade de acesso aos serviços de saúde existentes.

\section{Objetivo e método}

Buscar a compreensão de um projeto de intervenção social por meio do estudo dos encontros propiciados por ele e traduzidos em discurso pelos seus atores utilizando os eixos de sustentação da proposta para analisar suas falas.

O instrumento escolhido para se obter o material deste estudo foi a entrevista aberta. Para obter falas que tratassem dos conteúdos desejados e garantir discursos mais fiéis à realidade e não racionalizações foi apenas solicitado ao sujeito que relatasse seu trabalho no dia a dia. 
O estudo foi realizado na cidade de São Paulo com profissionais das equipes de PSF de diferentes regiões, parcerias e históricos. As entrevistas com representantes das categorias fundamentais das equipes do PSF foram gravadas em áudio e transcritas integralmente. Participaram: 13 (treze) ACS (agentes comunitários de saúde), 8 (oito) auxiliares de enfermagem, 3 (três) enfermeiras e 2 (duas) médicas, o que totalizou 26 (vinte e seis) entrevistas. Conforme compromisso assumido no momento de assinatura do consentimento, cada entrevista foi identificada com uma sigla que permitisse saber apenas a categoria profissional.

Os textos obtidos foram recortados segundo os temas abordados e foi constituído um discurso único relativo a cada um deles. Pretendeu-se verificar a partir desta seleção como se constituem estes discursos, qual a sua extensão e como se fala. Com os conteúdos referidos nos recortes procurou-se observar as ideias relativas aos temas e como se expressam. O que se buscou apreender foi como o grupo estudado constrói interpretações da realidade: da sua própria atuação, da atuação do programa, de si, do outro e das relações promovidas pelo trabalho no PSF.

Por se tratar de um estudo em Psicologia Social, não há preocupação com conteúdos individuais, mas como cada discurso, composto das diversas falas, expressa ideias e valores de um dado momento sócio-histórico e como este conteúdo determina a forma com que ocorrem (e se ocorrem) as mudanças previstas. Por isso os recortes das falas não são identificados uma vez que foram agregados para constituir discursos coerentes com as ideias apresentadas.

Foram escolhidas as diretrizes do programa como categorias de análise das falas: participação comunitária; trabalho em equipe; integralidade; equidade; intersetorialidade e humanização e vínculo com a população, esta categoria não prevista, mas que se destacou pela presença e extensão das falas. Associadas aos outros achados elas poderiam clarear o desenho facilitando a compreensão do processo.

$\mathrm{Na}$ leitura inicial percebeu-se que a referência a si mesmo e a menção às outras pessoas expressando concepções próprias era constante nos vários depoimentos. A ideia de que a visão de sujeito apresentada nos discursos poderia fornecer conteúdos importantes para fundamentar e discutir outros aspectos observados foi determinante para incluí-la como uma nova categoria.

\section{Análise dos depoimentos}

As categorias foram agrupadas em dois grandes blocos temáticos: concepção do trabalho e de sujeito. Sob o primeiro tema estão reunidas categorias que dizem diretamente das atividades do PSF, aquelas derivadas das diretrizes do programa. No segundo, as ideias de como são vistas as pessoas envolvidas. 


\section{Trabalho}

Na primeira categoria apresentada, estão trechos das falas que se referem à participação da comunidade nas atividades do PSF. São compreendidas em dois grupos maiores:

No primeiro, participação é entendida como a criação de parcerias para campanhas ou atendimentos de saúde que faltam na comunidade:

Quando a gente tem reunião... com a comunidade, eles abrem espaço pra gente.

A segunda ideia é a de participação como representação formal, no caso nos conselhos gestores, ou da unidade e até dos âmbitos maiores:

com o PSF, tem o conselho gestor... tem as pessoas interessadas que representam as outras pessoas... aqui tem as pessoas do conselho gestor de saúde, toda a unidade de saúde tem que ter, que são pessoas representantes da comunidade.

As ideias de participação aparecem de forma dispersa nos vários discursos, mas o enfoque majoritário está localizado nos problemas e tarefas de saúde que a equipe identifica e para os quais deve encontrar respostas dentro de padrões conhecidos e, para tanto, a população deve se juntar aos esforços para aumentar a eficácia/eficiência do programa. Não se observa nos discursos preocupação em levantar com a população quais os problemas que esta percebe como determinantes na realidade de saúde de seu território. As agentes de saúde, que têm histórico de mobilização da comunidade, não integram este aspecto na realização do trabalho da equipe.

Na segunda categoria estudada, visão do trabalho em equipe, observou-se que se referem à equipe como um conjunto dado de profissionais que interagem a partir de um modelo tradicional de divisão de tarefas, quase sempre relacionadas à assistência, ao acompanhamento dos casos, ou à organização das atividades. Não se percebe a possibilidade de um grupo como construção a partir de um encontro de pessoas diferentes com saberes diferentes. Poucos explicam como a equipe se organiza para trabalhar, mas é possível deduzir que o trabalho é focado nos casos e, quase sempre, se centraliza na figura do enfermeiro e na do médico. Sobre a equipe, no geral o discurso mais frequente se refere às reuniões, que são descritas, na maioria para socializar informações, ou mesmo, para prestar contas das atividades:

um enfermeiro, um médico, cinco agentes comunitários, dois auxiliares de enfermagem e um administrativo. Essa equipe se reúne diariamente... a reunião que a gente marca por semana é pra contar os problemas que tem na comu- 
nidade pro médico e enfermeira... Quem teve bebê, quem não teve, quem chegou, quem agregou. E passa algum óbito se houver, alguma internação... O trabalho de equipe é esse... cada um passa um pouco do que aconteceu durante o dia.

Todas as categorias profissionais expressam-se de maneira semeIhante, relacionando a socialização das informações à funcionalidade do programa e à agilização dos procedimentos. Em alguns casos é salientada a importância das reuniões para resolver conflitos que aparecem entre as pessoas da equipe, ou mesmo para evitá-los tentando uma uniformização das abordagens.

As ideias apresentadas não revelam grandes inovações como as projetadas para o programa. Mas percebe-se que, embora a equipe seja mencionada como conjunto pronto e acabado, há uma dinâmica no sentido de serem realizadas tentativas de superação dos obstáculos encontrados no dia a dia incluídos no âmbito da qualidade das relações e centrados na questão dos relacionamentos ou características pessoais.

A categoria humanização/vínculo reúne as ideias recolhidas nos depoimentos que dizem respeito aos elos estabelecidos com a população atendida que determinam uma forma de assistência mais pessoal. A maior ênfase é dada para a humanização do atendimento, que incide na humanização deles próprios e que é referida como a possibilidade de um trato pessoal entre eles da equipe, e as pessoas da população.

Pode-se pensar que nesta categoria se manifestam mais fortemente as ideias de cuidar que embasam o PSF tal como entendem os profissionais, tanto no que se refere a oferecer informações, orientação, atenção e cuidado que exige e, ao mesmo tempo, acarreta uma proximidade maior com o usuário.

A humanização do atendimento e o vínculo dos profissionais com a população se confundem no discurso e, como aparecem, sugere que há uma interpretação de que a humanização deve se ancorar no vínculo que é estabelecido com a população.

Percebe-se que, independente da categoria, há um envolvimento emocional bastante forte com as dificuldades pelas quais passam as pessoas da população que, às vezes, se reflete no teor emocional do relato. Algumas situações parecem tomar-lhes intensamente e ganham uma dimensão maior com os ACSs que têm contato cotidiano com elas. Responder às dificuldades com ações concretas pode aliviar, assim como o cuidado oferecido também pode reverter o que era vivido como sofrimento invasivo.

Então é uma coisa tão grande, tão diferente, que quem tá fora não tem nem noção do que realmente é o nosso trabalho... Aí a pessoa começa a contar toda a vida dela:? porque ontem meu filho morreu, foi assassinado, ou porque 
ontem o meu marido foi preso, então você entra na vida da pessoa de uma tal forma que não tem como você criar um laço afetivo com a pessoa. E isso torna o trabalho difícil porque às vezes a gente tem que se trabalhar pra não levar tudo isso pra sua casa... Você vê criança passando fome e aí você acaba se envolvendo até mais do que a profissão muitas vezes exige... Coisas que ele jamais pensaria em contar pra uma pessoa desconhecida, ... eles já têm essa confiança. Eles contam tudo, alguns anseios, algumas tristezas, alguma coisa que tá acontecendo na casa... filha, preciso te contar... foi fulano que chegou bêbado, me bateu... não, é só profissional... viu... Então é difícil trabalhar, mas é gostoso, é suado, porque depois que você se apega a essas famílias você pega aquele ciclo de famílias suas. É nossa também. Então a gente tem que fazer aquilo que gosta com amor e com carinho.

E se observa que o vínculo é descrito como de mão dupla, do profissional com a população e desta com a equipe:

É compreensão das pessoas também. Essa compreensão... ajuda até pra gente poder fazer o nosso trabalho... Então eles sabem que tem uma amiga, que pode contar com aquela amiga.

A proximidade permite mais, permite conhecer as condições de vida e especialmente as histórias, o que fortalece ainda mais os laços e pode contribuir para a assistência e o tratamento. Este é um aspecto que se torna possível principalmente pelas visitas e que é visto como um diferencial do serviço:

A gente precisa conhecer a pessoa, o que, que ela faz, qual o estilo de vida dela, pra poder falar depois o tratamento da doença que ela tem.

A intimidade proporcionada pelo conhecimento mútuo e pela confiança depositada no profissional parece possibilitar maior facilidade para obter os dados vitais sobre a pessoa porque ela se torna mais disponível para abri-los e sente-se mais cuidada, além de melhor aceitar as orientações. De alguma forma, há uma compreensão que o tratamento humanizado, por meio do vínculo, permite também uma abordagem integral e dessa forma pode influir na condição de saúde da pessoa.

Outro aspecto verificado é o de como o reconhecimento do outro, que se expressa às vezes como agradecimento, reforça o sentimento de pessoalidade, de envolvimento e de intimidade entre os atores envolvidos na interação. Para os trabalhadores do PSF, o vínculo propiciado é um fator de satisfação pessoal.

então é muito gratificante você entrar na unidade e você receber esse paciente, às vezes o paciente vem te agradecer, vem te abraçar, te conhece na rua. Isso é muito gratificante. 
No item equidade procurou-se selecionar fragmentos em que pudessem ser observados os critérios que as equipes utilizam para determinar as prioridades da assistência, pois, embora se proponha um atendimento igualitário, não sendo possível oferecer vagas para todos, há que se fazer escolhas. Nos relatos a ideia de equidade se faz hierarquizandose as prioridades, para que as pessoas escolhidas a partir de diagnósticos médicos não deixem de receber a atenção devida.

A integralidade, no que se refere à abordagem integral do ser, em todos os aspectos da vida, que inclui as condições socioeconômicas, parece que começa a ser vislumbrada nos discursos e a serem esboçadas formas para esse atendimento.

Uma diretriz preconizada para o programa, a intersetorialidade, que depende das ações da equipe com outros setores, começa a se desenhar como um pequeno esboço em alguns trabalhos descritos, mas ainda como resposta a uma solicitação, um serviço prestado pela equipe de saúde e não como um projeto comum construído para dar conta de um problema identificado no território.

\section{Sujeito}

O PSF, uma proposta desconhecida para aquelas pessoas quando foram contratadas no momento em que é implantada, se torna real por intermédio delas, que trazem suas marcas (de seu tempo, de sua cultura) nas relações que vão construindo. São elas que se revelam nos discursos sobre o programa, que revelam essas marcas, que dizem de si, das suas ideias, dos modelos que adotam não apenas nas suas ações, mas também no que prescrevem e no que repudiam e recriminam. O PSF torna-se essas próprias pessoas no que elas estão fazendo e compreendendo. Há falas explícitas de identificação com o programa:

Um programa bom e que tem que ter pessoas que se identificam, se você não tiver identificação... Identificação é você gostar do que está fazendo.

Foram selecionados, neste trecho, falas dos trabalhadores em que, explicitamente, expressam pensamentos relacionados às ideias de sujeito, de si e do outro, tanto da equipe quanto da população e da forma que eles se relacionam ou deveriam se relacionar. Procurou-se agrupá-las, então, segundo a visão de si, do outro e das relações.

O conteúdo relacionado à ideia de sujeito referida a si mesmo, foi trabalhado a partir de como relatam que realizam seu potencial na construção do trabalho e de si, e como expressam sentimentos e sensações vividos neste contexto. 
Aparecem neste próximo trecho conteúdos que sugerem o que e como podem efetivar a potência: de passar informações para tentar mudar os comportamentos ou conscientizar:

gosto de aprender muita coisa e também gosto de passar, então foi legal, eu gosto dessa parte de cuidar das pessoas... porque de fato eu acho que a gente tem que ser mais ou menos um orientador pras pessoas... fechar esse ciclo de informações... dizem que hoje as pessoas não aceitam a informação picada, aceitam a informação por completo... como que transmite e como evitar... encontrar uma forma de fazer com que ela tome o remédio pra pressão.

Também incentivar ou censurar para efetivar mudanças:

então a gente convida essas pessoas e avisa... A gente incentiva: $3 / 4$ venha também, dá uns puxões de orelha nos pacientes também.

Aí a gente começa a colocar um pouco de medinho assim na pessoa. Uma pressão psicológica, não sei.

Mobilizar é uma ação que julgam poder ser eficaz em alguns casos:

o trabalho da gente é mobilizar a comunidade. Não só pros grupos, mas também assim, a comunidade que tem problema de saneamento básico... ir buscar também perante aos órgãos competentes.

Mas, às vezes o que resta é rezar:

Eu tenho dó, sinceramente, eu tenho muita dó... Rezo, porque o coração corta.

Aqui se explicitam sentimentos e sensações que os profissionais relacionam às vivências nas ações do PSF:

De uma forma ou de outra, você tá colaborando... pro meu ego fez muito bem... porque eu me sinto bem em ajudar... Como pessoa também, porque eu gosto de ajudar as pessoas... às vezes, assim, emocionante, às vezes estressante. Mas tem dia que me traz muitas alegrias... tem situações que dá muito prazer, você fica muito contente, mas também tem vezes que te deixa triste porque você vê alguma coisa que acontece e que não é legal ... é um monte de sentimentos misturados.

Os próximos trechos apresentados referem-se às ideias que expressam a visão sobre o outro.

Em relação ao outro - população atendida, as ideias prevalentes são as de carência: 
Porque na nossa área que é uma população muito carente a gente não tem ajuda da família, são pacientes difíceis... e é um paciente resistente... Anos pra você conseguir mudar alguma coisa... porque a população é muito carente... Carência de atenção, carência afetiva, carência... financeira... A carência na verdade da população aqui do bairro, dos que mais precisam de atendimento, a carência deles na realidade é a vida sócio econômica deles mesmo... São pessoas carentes de tudo, de amor, de carinho, e no geral, é uma população carente em todos os aspectos, não só financeiro, mas também na parte afetiva, de amor, de tudo, familiar.

O usuário também é visto como problema:

a mente deles confunde muito rápido, principalmente aquelas famílias que têm alcoolismo, confundem muito... que eles não sabem distinguir se uma gripe é uma doença, se um mal estar é uma doença, a procura que eles fazem é por coisas, assim, o mais absurdo que você imagina

Mas às vezes a pessoa é teimosa, ela não vem nem nas consultas que você marca.

Relatos de ações de ajuda ocupam grande parte dos depoimentos, que foram ressaltados em razão da presença significante nas falas:

Como pessoa também, porque eu gosto de ajudar as pessoas. Eu sempre gostei, eu sempre quis ajudar mais até do que eu ajudava na comunidade... Acho que todo dia quando você pode ajudar, quando você sabe que está fazendo alguma coisa útil pra pessoa, é especial. O paciente sabe que você está ajudando... Mas às vezes, ajudar uma pessoa é sorrir, conversar, dar atenção. Não só chegar, levar um remédio, chegar e levar o médico na casa. Que ele se sinta que tá sendo cuidado, mostrar pra ele que ele tá sendo cuidado, que tem alguém se importando com ele... então ela sabe que: pra eu ficar bom, eu tenho que fazer isso. Então isso ajuda bastante... porque a gente tá ali pra tentar ajudar, a gente não tá ali pra brincar.

Como observado acima, referem a si, quase sempre, procurando mostrar sua identidade com o programa naquilo que consideram altamente valorizado nele, ou seja, o encontro pessoal propiciado, que lhes permite ao mesmo tempo se revelarem humanos e oferecer ao outro uma imagem de si que parece ser altamente positiva sempre referida ao aspecto da ajuda, o que ganha uma dimensão de significado de si, de preenchimento da existência. Além disso, os depoimentos passam a ideia de recuperação imaginária da sua potência por meio da sensação efetiva de ser capaz de realizar algo para o outro no PSF, mas o inverso também se manifesta quando a impossibilidade de "resolver"torna-os frustrados, o que é mencionado raramente. A imagem de si parece necessitar de uma reafirmação contínua pelo outro, na forma de reconhecimento, agradecimento. 
O outro, especialmente aquele que procura ou que precisa do serviço, é caracterizado por faltas, carências, necessidades, desconhecimento, enganos e mentiras, embora em alguns momentos, parece que eles próprios se veem descritos dessa forma, ou relatam as relações como de preenchimento das necessidades mútuas. As descrições das necessidades quase sempre são referenciadas em linguagem psicológica e algumas expressões, muito em uso atualmente no espaço da mídia, passaram a ser apropriadas nesses discursos.

A relação com o outro é descrita por ações como: acolher e conversar, orientar, informar, ajudar aquele que não tem, preencher as faltas com conteúdos na forma de prescrições sobre a saúde e doença e que eles julgam Ihes seja restituído o poder de ajudar, desde que o outro cumpra a sua parte, ou seja, não adoeça; obter o reconhecimento do outro, sobre o seu verdadeiro interesse, que pode se manifestar apenas em ouvi-lo ou não poupar esforços para resolver todas as dificuldades que se colocam para esta população ao enfrentar situações relacionadas a alguns tratamentos médicos ou mesmo das condições necessárias à manutenção da saúde.

A relação entre esses dois segmentos, delimitados no discurso pelo próprio sujeito e a pessoa atendida, é marcada por lugares diferentes, 0 do primeiro como daquele que tem algo, ou a disponibilidade, ou a informação, ou o conhecimento e saber, ou mesmo, o poder de facilitar o acesso; e o outro que depende do primeiro para tentar conseguir atenção, e não apenas de uma consulta, ou exame, difíceis no seu meio, mas poder também significar seu sofrimento. Permeada pelo lugar institucional que diferencia essas duas pessoas, a relação, como nos é apresentada, permite compreender que os sujeitos desses discursos naturalizam o mundo social ordenado de forma hierárquica, em que as pessoas, ocupando lugares diferentes, têm poderes diferentes para decidir.

\section{Síntese dos resultados}

Numa leitura geral das entrevistas, percebe-se que o enfoque predominante é o da intervenção terapêutica, embora se considere que algumas atividades realizadas, como caminhadas, grupos informativos sobre diabetes ou hipertensão, poderiam ser incluídas naquelas de prevenção de agravos ou promoção de saúde, como propiciar informações ou meIhores condições para garantir eficácia terapêutica.

Os depoimentos referem-se, majoritariamente, às pessoas e aos casos pessoais, embora o programa tenha sido formulado com enfoque familiar e as visitas ocorrem às famílias nas residências.

Pelas observações, é possível considerar que os conceitos vigilância em saúde e territorialidade se apresentam restritos, pois as ações de- 
senvolvidas não podem se constituir em projetos para lidar com as questões epidemiológicas uma vez que a compreensão do território serve apenas para demarcar áreas de atuação das equipes e pouco ou nada para planejar e executar ações voltadas para aquele espaço. Parece que em alguns casos há um esboço de compreensão derivado de observações empíricas, mas não resultam em propostas para lidar com estas questões.

A adscrição da clientela parece ser um conceito que se cumpre, porque a ação dos agentes é incisiva, embora apareçam relatos de recusas, especialmente em pequenas áreas onde alguns bolsões de violência dificultam sua atuação. Mesmo em áreas privilegiadas, onde grande parte pode aderir ao sistema privado, tem se conseguido alguma forma de adesão.

O acesso da população às ações desenvolvidas nas unidades de saúde parece ter sido facilitado nesta nova proposta, pois o contato inicial na residência e a proximidade observada entre profissional e usuário parecem ser fatores que possibilitam ou reforçam a confiança no atendimento recebido, o que favorece a busca de assistência. Pelos relatos observa-se que a comunidade pode sentir-se mais à vontade dentro da unidade, inclusive para reclamar, mas sua efetiva participação no diagnóstico e planejamento das ações não acontece, porque a população não é vista como capaz desta tarefa e não há formulação para esse processo. Neste aspecto, outros estudos corroboram estes achados (Ronzani \& Silva, 2008; Valla, 1998; Crevelim, 2005), pois se observa que os profissionais compreendem a população como responsável pela sua condição de exclusão.

Quanto à integralidade, na perspectiva de uma abordagem integral do indivíduo como cidadão nas suas relações familiares e sociais mais amplas, as falas indicam um processo de construção dessa visão facilitado pelo conhecimento do usuário no seu "locus." Na perspectiva do sistema de saúde, à integralidade se interpõem obstáculos nas várias instâncias, das dificuldades dos profissionais do programa que não apresentam habilidades para lidar com questões que fogem do âmbito técnico como as negociações e a desorganização do sistema que não garante as conexões entre os vários níveis.. Embora no PSF as ações de prevenção e promoção ocupem um lugar maior, ainda estão referidos na dentro da visão "hospitalocêntrica", para esvaziar o hospital.

A partir das falas obtidas foi possível definir aqui vínculo como uma forma de aproximação do profissional com as pessoas da população em que ele se implica nos problemas observados e na busca de sua solução, o que traça uma identificação com a proposta do PSF.

Quanto à humanização, este é um termo que tem recebido críticas, pois além de não ter uma definição diferenciada, a conotação constrói seu sentido excluindo características humanas indesejáveis do ponto de vista do modelo social vigente, que nega conflitos e contradições. O signi- 
ficado do termo neste estudo na categoria humanização/vínculo foi restrito à seleção de falas que expressavam ideias de envolvimento pessoal no trabalho, especialmente com as pessoas assistidas, quando havia referência a si como sujeito implicado nos problemas vivenciados por elas. Essa forma de compreensão de ser humano na relação com o outro que levou a integrar as duas ideias na mesma categoria.

O vínculo com a população é, então, o eixo sobre o qual se sustentam as ações do PSF. Acrescentando os estudos sobre a concepção de sujeito, buscando a compreensão das relações entre o segmento dos trabalhadores e a população, pode-se apreender que as ações realizadas e, que têm como retorno satisfação por permitir a experiência de poder, são aquelas voltadas para o cuidado e a ajuda, no que compreendem que as pessoas atendidas por eles necessitam. A forma como são apresentados os relatos de casos com resultados positivos - cura ou melhora - revela que isso também influencia no sentimento. Estudos que abordam este tema reforçam a ideia de que o vínculo e a confiança estabelecida entre profissional e usuário são aspectos importantes na ampliação do cuidado na perspectiva da assistência no PSF (Oliveira, et al., 2008; Uchoa, 2009).

A base sobre a qual se poderia traçar um panorama obtido a partir das entrevistas é, sem dúvida, a motivação de ajudar, que se manifesta explicitamente em todas elas. Situações extremamente precárias observadas de muito perto mobilizam a busca de dirimir o sofrimento, especialmente aquele da dor provocada pela doença ou pela falta de assistência. Pode-se perceber que o trabalho é afetado muito de perto pela dor do outro que se coloca numa posição de receber a ajuda disponível na equipe. Longe de refletir o que leva a essa situação e quais são seus determinantes, há que se diminuir essa dor que acaba atingindo também o profissional. Mas a possibilidade de alguns deles perceberem que esta forma de agir tem um retorno desejado, o que significa para eles também poder receber ajuda, indica que esta motivação é anterior e não consequência desse encontro, pois poder ajudar parece ser um componente da identidade social bastante valorizado nessas pessoas.

É importante salientar que no campo da enfermagem o enfoque no aspecto da ajuda predomina e coincide com os princípios que regem sua prática na concepção da profissão como vocação ou doação, e que a torna idealizada a partir de elementos como satisfação profissional e motivação. Segundo artigo de Carvalho (2003), a origem religiosa da profissão poderia ser um fator explicativo e se refere à arte da enfermagem, que "se consolida no encontro da enfermeira com seus clientes. Arte que se concretiza no plano da relação de ajuda e da totalidade da prática de enfermagem" (Carvalho, 1980, citado por Carvalho, 2003, p. 3). Essas informações vêm incrementar a discussão sobre o caráter de ajuda que parece bem fincado nos aspectos culturais dos segmentos envolvidos. 
Wuthnow (1996) realizou um estudo sobre atos de compaixão, em que levantou as razões pelas quais as pessoas envolvidas explicam suas ações, e uma das primeiras observações é que são compatíveis o individualismo e a compaixão. Entre as explicações apresentadas está a natureza humana e o argumento religioso ou metafísico. Outra linha de argumentação que o autor apresenta é que "La mejor razón para la compasión no es que nos beneficie de alguna forma tangible o material, sino que nos proporcione satisfacción personal" (pp. 357-358)' ${ }^{1}$. Ainda mais forte é o entendimento dessas ações como contribuição social em que pode haver um retorno não imediato, ou seja, se entende que "se siembra y se recoge" (p. 368) ${ }^{2}$, de forma a constituir uma rede em que se incluem todos os segmentos sociais que se beneficiam.

O argumento da satisfação pessoal colocado por Wuthnow (1996) parece ser consistente para entender a relação de ajuda entre profissional e usuário, pois o remete ao legado cultural e, na tradição religiosa de nossa sociedade, a caridade permanece ainda como um valor importante na construção de imagens positivas com as quais pode haver a busca de identificação.

O sentido de ajuda observado nas ações relatadas é o de fazer para e pelo outro ou estar o mais próximo possível para acompanhar se este outro cumpre os preceitos determinados pelo serviço de saúde para combater as doenças. Não se percebe nos relatos uma forma de ajuda para possibilitar ao outro, num momento posterior, construir um destino autônomo. Viver na sociedade do "powerlessness", que provoca sensações de desamparo e impotência, a função de ajudar pode ser a de recuperar, imaginariamente, o próprio poder, mas que impede o outro de ver o poder dele próprio e assim alimenta um ciclo.

Este é o modelo de encontro propiciado pelo programa: de tentativa de preenchimento das faltas e carências, aquelas reconhecidas no imediato da relação e que Campos (2003) entende que propicia o vínculo entre população e profissional. $O$ vínculo também estabelece uma relação de poder porque, os profissionais ao preencherem aquilo que uma população sem nada (ou com pouco) busca, constroem sua potência nessa relação e a possibilidade de estabelecer dependência é muito maior do que criar autonomia ou emancipação. Também Campos (2003) refere a essa diferença de poder como relações com "super herói" todo poderoso ou com um "santo", torna os do outro lado como "coitados" que dependem do heroísmo ou "resignados" da caridade. Aqui, parece haver uma aproximação da ideia de caridade que pode levar ao risco de ser confun-

1 "A melhor razão para a compaixão não é que nos beneficie de alguma forma tangível ou material, mas que nos proporcione satisfação pessoal" (tradução nossa).

2 "se semeia e se colhe" (tradução nossa). 
dida com clientelismo e impedir que se compreenda a atenção recebida como um direito estabelecido por normas jurídicas que permite ao usuário sentir-se cidadão com possibilidade de superar a vivência de favorecimento.

No caso das doenças crônicas em que o seu agravamento conduz à piora nas condições de vida com exacerbação das situações de miséria pessoal e social, o que se busca é que o paciente, diante desse diagnóstico, passe a adotar atitudes adequadas para evitar a evolução da doença. Isto implica em mudanças, às vezes, bastante sérias na conduta de sua vida e para que isto aconteça, eles são cobrados frequentemente e recebem acompanhamento direto, segundo os relatos ouvidos nas entrevistas. Então, as ações que definem melhor nosso esboço são de controle intenso sobre esses pacientes, no sentido de dominar essa situação, mesmo sem saber como nem o que significa a situação para o paciente. Não se manifesta a preocupação em saber qual é a verdadeira compreensão que o paciente tem sobre o diagnóstico, o funcionamento do seu corpo, a lógica que orienta a evolução da doença. Contar com sua participação parece ser, na verdade, esperar uma adesão cega às verdades apresentadas a ele. $E$ essas verdades são as que provêm do conhecimento construído pela medicina e a partir dos quais se cria uma linguagem comum, orientam-se as opções e a escolha das prioridades, inclusive as de ajuda.

O sentimento de proximidade com as pessoas que recebem assistência é o que vem completar este quadro. No PSF, a população daquele território é mais do que o cadastro de fichas do posto, as pessoas têm realidade no lugar onde vivem e lhe dão o seu tom, seu odor, seu tempero, que compartilham com os ACS e se abrem nas visitas criando intimidade, possibilitando em troca o reconhecimento pelos cuidados dispensados, que até os "bandidos" respeitam. Nas narrativas verifica-se que esses trabalhadores percebem que o contato com as pessoas no local de vida torna-se uma forma de atuação que supera a burocracia e a rotina observada nos demais setores da saúde.

No material obtido, pode se perceber que as doenças se mantêm num lugar privilegiado, e parece ser em torno dessas preocupações que as equipes se organizam, pensam e dão sentido a suas ações. A perspectiva curativa predomina e em muitos casos há manifestações de insatisfação, pois os profissionais preferiam atuar preventivamente, mas justificam que as condições encontradas pediam intervenções rápidas. $\mathrm{O}$ aspecto assistencial busca responder aos anseios da população que procura atendimento para problemas imediatos e específicos e apresenta ainda dificuldades para entender e aderir às abordagens preventivas. $O$ estudo de Ronzani e Silva (2008) corrobora estas observações, e também é observado por Sousa e Hamann: 
não conseguiu, ao longo dos doze anos de implantação e implementação, ampliar as condições para a superação efetiva do modelo biomédico hegemônico nas políticas públicas do setor saúde no Brasil. (Sousa \& Hamann, 2009, p. 1334)

\section{Outros achados}

As interpretações psicológicas sobre situações de sofrimento ou incapacidades são muito frequentes nas falas, o que sugere terem sido incorporadas com mais facilidade e evidencia a supremacia que atingiu essa forma de explicação sobre o funcionamento do corpo e demais fatos pessoais e sociais, determinando olhares que moldam os contornos dos fenômenos identificados como questões psicológicas.

Furedi (2004) define como "therapy culture" a invasão da linguagem do emocionalismo na cultura popular, no mundo político e nos vários espaços sociais. Ele verifica como uma tendência contemporânea no mundo ocidental deste fenômeno de expansão de estilos psicológicos e terminologia terapêutica. Essas mudanças foram ocorrendo gradualmente nas últimas três ou quatro décadas. "In an age where emotionalism has acquired a formidable cultural status, it is important to remember that society is selective about which emotions it embraces and which it rejects" (pp. 30-31)

Semelhanças bastante intensas nas falas e não apenas nos conteúdos, mas até nas expressões utilizadas, foram observadas nos depoimentos. A cultura de massa como explicação não é suficiente, mas a definição de hegemonia de Gramsci apresentada por Rubin "como direção intelectual e moral, por conseguinte (a política inclusive) como lugar onde se acionam ideias, valores, emoções, interesses, etc" (Pitta, 1995, p. 82), pode contribuir, para entender esse fato. Os conteúdos apresentados compõem uma visão hegemônica do atual momento histórico, retratada neste caso como a convergência discursiva observada em torno dos temas centrais como ajuda, carência, educação/informação.

\section{Reflexões finais}

Ações desconectadas das ideias de território, doenças como foco do projeto em resposta às necessidades imediatas, compreensão das pessoas da população em estereótipos - carentes - o que implica em relação de ajuda como preenchimento das carências em uma identificação/empatia com a dor de não ter, ou como possibilidade de "recupera-

3 "Em uma época em que o emocionalismo adquiriu um status cultural terrível, é importante lembrar que a sociedade é seletiva sobre quais emoções ela acolhe e quais rejeita" (tradução nossa). 
ção" da potência da equipe, constituem uma síntese dos resultados. $O$ que desse conteúdo não faz parte do modelo hegemônico do pensamento ou do condicionamento das emoções?

Na sua execução, o programa torna-se um espaço de socialização que se funda na interiorização e observação de novas regras higiênicas para a construção de um modelo de saúde/organização política em que as pessoas se responsabilizam individualmente pela própria saúde. Este modelo seria construído a partir de um sujeito desejável em que, pelo convencimento, deveria interiorizar as regras, sustentado no vínculo de confiança com o trabalhador. A base de sustentação é, dessa forma, uma construção afetiva/emocional sobre a qual se pretende produzir sujeitos "menos resistentes" para consertar as condições de produção das doenças. O conhecimento biomédico, produzido no universo técnico-científico no interior de práticas estranhas à população alvo, se expande vinculado à aceitação do outro, pela intermediação do agente de saúde que adquire prestígio social à medida que recebe alguma formação dentro dessa área.

O PSF dos discursos recolhidos é o programa que se concretiza no trabalho cotidiano pelo desejo, intenção e compreensão das pessoas entrevistadas. Mas, vai além, pois é o espelho utilizado por elas para refletir a imagem que construíram de si, seus valores, seus ideais, seus preconceitos, que modulam as relações que estabelecem com o próprio trabaIho, com as pessoas da comunidade, da equipe e da instituição. Pode-se perceber que o PSF é uma projeção idealizada de si naquilo em que a proposta busca dar conta de atender à pobreza, superar a iniquidade, de possibilitar ouvir a dor, portanto, é o lugar onde a ajuda se realiza como expressão de um valor social que coincide com aquele selecionado para fazer parte das imagens pessoais por meio das quais essas pessoas se veem e se reconhecem como sujeitos nas interações sociais.

Ao atuar no Programa de Saúde da Família, dando conta de assistir às pessoas nas suas necessidades ou consertando condições entendidas como geradoras das doenças por meio da mudança do outro, os profissionais vivenciam a relação que estabelecem como de ajuda, o que permite a eles reincorporar a potência, à medida que se sentem realizando algo, que são capazes de interferir na realidade e que, portanto, podem se reinvestir do sucesso, outra categoria hegemônica que parece sustentar as sensações descritas como de satisfação pelos resultados obtidos e que os nutre reforçando o envolvimento com o programa.

Reconhecer os valores, ideais, emoções e preconceitos como elementos da cultura do nosso tempo acionados a partir do centro hegemônico, que constituem o material com o qual se constroem as subjetividades ou as matrizes identitárias dos sujeitos contemporâneos, nos permite começar a compreender como a organização sócio-política se constitui e se mantém na interiorização desses aspectos, mas fundamen- 
talmente na naturalização desse processo. Um projeto de intervenção pode possibilitar mudanças realmente significativas ao se propor a explicitar esse jogo de poder, pois a adesão cega nada mais é que a alienação no status quo, sustentado pelas crenças nos ideais de virtude.

Ao se compreender que a configuração social, em todos os aspectos que isso implica, determina não apenas os pensamentos, as relações, mas conteúdos e lugares de desejo, moldando identidades e desenhando as narrativas que vão constituir a realidade naturalizada a partir de conceitos hegemônicos disseminados em determinado momento histórico, o PSF não escapa a essa determinação. Como proposta que reúne pessoas com diferentes histórias, se pudesse ser concretizado como um espaço de locução que permitisse deixar emergir as diferenças para desvelar as determinantes sócio-político-históricas na construção das identidades, poderia então tornar-se um projeto de intervenção com potencial para as desejadas mudanças no status quo. Para isso deveria propiciar um processo de reflexividade baseado em interações pessoais não permeadas pela racionalidade instrumental do conhecimento da biomedicina.

Social Intervention Project Analyzed Through its Agents - A Psychosocial Study of the Program Health in the Family

Abstract: The Program Health in the Family (PSF) was selected as the object of the present study because it is a social intervention project that aims to promote social changes directed to increasing the community's autonomy concerning the solution of health problems in the territory. The acquired material within interviews with these professionals was analyzed through categories grouped in two thematic blocks: work conception - the ones that refer to the activities, and the fellow ones - where are brought together the ideas about the involved people. The contents analyzed reveals that the program doesn't reach the foreseen changes. The territory concept is incipient, the participation is precarious and the illnesses are maintained in privileged place. The population's people are refereed in a collection characterized by lacks, absences and needs, in many cases, are identified as the interviewed people themselves. The help mobilize the actions; it is the axle from which the actors understand his acting itself.

Keywords: Health in the Family. Social intervention. Psychosocial study. 
Un projet d'intervention sociale vu par ses agents - etude psychosociale du Programme de Sante de la Famille

Resumé: Le Programme de Santé de la Famille (PSF) a été choisi comme l'objet de cette étude, étant donné qu'il s'agit d'un projet d'intervention sociale qui prétend promouvoir une plus grande autonomie de la population, afin de résoudre les problèmes de santé dans le territoire.

Le materiau obtenu lors des entrevues avec des professionnels a été analisé par catégories regroupées en deux blocs thématiques: conception du travail, ceux qui se rapportent à des activités, et sujet - où les idées se rejoignent sur les personnes concernées. Les contenus montrent que le programme n'a atteint pas les changements envisagés. La notion de territoire est naissant, la participation est précaire et les maladies restent en lieu privilégié. Les gens de la population sont referées à un ensemble caractérisé par la pénurie, defaults et besoins, et, dans bien de cas, elles sont identifiées aux interrogés lui-mémes. L'aid mobilise les actions; est l'axe à partir de lequel les acteurs comprennent leurs propres actions.

Mots-clés: Programme de Santé de la Famille. Intervention sociale. Étude psychosociale.

Un proyecto de intervención social, como sus agentes lo ven - Estudio psicosocial del Programa de Salud de la Familia

Resumen: El Programa de Salud Familiar (PSF) fue elegido como objeto de estudio porque es un proyecto de intervención social que tiene como objetivo promover una mayor autonomía de la población para resolver los problemas relativos a la salud en el territorio. El material obtenido en las entrevistas con los profesionales se analizó mediante categorías agrupadas en dos bloques temáticos: el diseño del trabajo - las lineas que se refieren a las actividades, y el sujeto - donde se reúnen ideas acerca de las personas involucradas. El contenido muestra que el programa no llega a los cambios esperados. El concepto de territorio es incipiente, la participación es precaria y las enfermedades se mantienen en lugar especial. Se hace referencia a la gente de la población como un grupo que se caracteriza por fallas, deficiencias, necesidades, y en muchos casos, se identifican a los propios profesionales. La ayuda moviliza acciones, y es el eje desde el que los actores comprenden su propio desempeño.

Palabras clave: Programa de Salud de la Familia. Intervención social. Estudio psicosocial. 


\section{Referências}

Bousquat, A., Cohn, A. \& Elias, P. E. (2006). Implantação do Programa Saúde da Família e exclusão sócio-espacial no Município de São Paulo, Brasil. Cadernos de Saúde Pública, 22(9). Recuperado em 07 de janeiro de 2010, de http:/ /www.scielo.br

Brasil. Ministério da Saúde. Secretaria de Atenção Básica. (2001). Programa de Saúde da Familia. Brasília, DF:Autor. Recuperado em 30 de novembro de 2003, de http://www. saude.gov.br

Brasil. Ministério da Saúde. (2006). Portaria no 648, de 28 março de 2006. Recuperado em 29 de dezembro de 2009, de http://www. saude.gov.br

Brasil. Ministério da Saúde. Secretaria de Atenção à Saúde. (2003). Programa Saúde da Família: ampliando a cobertura para consolidar a mudança do modelo da Atenção Básica. Revista Brasileira de Saúde Materno-Infantil, 3(1), 113-125

Campos, G. W. S. (2003). Saúde paidéia. São Paulo: Hucitec.

Carvalho, V. (2003). Enfermagem fundamental - predicativos e implicações. $R e$ vista Latino Americana de Enfermagem, 11(5), 664-671.

Crevelim, M. A. (2005). Participação da comunidade na equipe de saúde da família: é possível estabelecer um projeto comum entre trabalhadores e usuários? Ciências e Saúde Coletiva, 10(2), 323-331.

Faleiros, J. J. (2003). Profissionais para reorientar o modelo assistencial. Quantos e quais? Revista Brasileira de Educação Médica, 271), 55-64.

Furedi, F. (2004). Therapy culture - Cultivating vulnerability in an uncertain age. Londres: Routledge.

Kahassay, H. M., \& Oakley (Orgs.). (1999). Community involvement in health development: $A$ Review of the Concept and Practice. Geneva: World Health Organization.

Marsiglia, R. M. G., Silveira, C., \& Carneiro Junior, N. (2005). Políticas sociais: desigualdade, universalidade e focalização na saúde no Brasil. Saúde e Sociedade, 14(2). Recuperado em 08 de janeiro de 2010, de http://www.scielo.br

Oliveira, A. Silva Neto, J.C., Machado, M. L.T., Souza, M.B.B., Feliciano, A. B., \& Ogata, N. M. (2008). A comunicação no contexto do acolhimento em uma unidade de saúde da família de São Carlos, SP. Interface - Comunicação, Saúde, Educação, 12(27), 749-762. 
Pitta, A. M. R. (1995). Saúde \& comunicação: visibilidades e silêncios. São Paulo: Hucitec.

Ronzani T. M., \& Silva, C. M. (2008). O Programa Saúde da Família segundo profissionais de saúde, gestores e usuários. Ciência e Saúde Coletiva, 13(1), Recuperado em 07 de janeiro de 2010, de http://www.scielo.br

Sousa, M. F., \& Hamann, E. M. (2009). Programa Saúde da Família no Brasil: uma agenda incompleta? Ciência \& Saúde Coletiva, 14(Supl. 1), 1325-1335. Recuperado em 07 de janeiro de 2010, de http://www.scielo.br

Tassara, E.T. O., \& Ardans, O. (2003). Participação emancipatória: reflexões sobre a mudança social na complexidade contemporânea. Imaginário, (9), 15-31.

Uchoa, A. (2009). Experiências inovadoras de cuidado no Programa Saúde da Família (PSF): potencialidades e limites. Interface - Comunicação, Saúde, Educação, 13(29), 299-311.

Valla, V. V. (1998). Sobre participação popular: uma questão de perspectiva. Cadernos de Saúde Pública, 14(supl. 2), 7-18.

Veras, C. L. M., Rodrigues, R. M., \& Carvalho, A. L. B. (2000). O Programa Saúde da Família na Paraíba: do processo de implantação aos resultados. Divulgação em Saúde para Debate, (20), 26-34.

Viana, A. L. D., \& DalPoz, M. R. (1998). A reforma do Sistema de Saúde no Brasil e o Programa de Saúde da Família. Physis: Revista de Saúde Coletiva, 8(2), 11-48.

Wuthnow, R. (1996). Actos de compasión. Cuidar de los demás y ayudar-se a uno mismo. Madrid: Alianza. 
Ana Maria Blanques: Psicóloga da Secretaria Municipal da Saúde e pesquisadora no LAPSI- Laboratório de Psicologia Socioambiental e Intervenção do Instituto de Psicologia da Universidade de São Paulo. Endereço para correspondência: R. Conde de Irajá, n¹3, apto 32, Vila Mariana. CEP: 04119-010, São Paulo, SP. Endereço eletrônico: amblanques@gmail.com

Recebido: 04/03/2010

Aceito: 16/08/2010 